\title{
DESEMPENHO DE UM TRATOR AGRÍCOLA SOB DIFERENTES CARGAS E VAZÕES DE AR ADMITIDAS PELO MOTOR
}

\author{
Fábio Souza Gomes ${ }^{1}$, Elton Fialho dos Reis ${ }^{2}$, Ródney Ferreira Couto ${ }^{3}$, Vandoir Holtz ${ }^{4}$
}

\section{RESUMO}

O objetivo desse trabalho foi avaliar o desempenho energético, o rendimento na barra de tração e a eficiência de combustão em um motor de ciclo Diesel de um trator agrícola utilizando diferentes cargas na barra de tração e vazões de entrada de ar no sistema de alimentação. Assim, montou-se um experimento em delineamento inteiramente casualizado no esquema fatorial 5 x 4, constituído por diferentes cargas na barra de tração do trator $(2,7 ; 7,4 ; 11,9 ; 15,5$ e $20,5 \mathrm{kN})$ e diferentes vazões de ar admitida pelo motor $\left(0,077 ; 0,085 ; 0,099\right.$ e $\left.0,109 \mathrm{~m}^{3} \mathrm{~s}^{-1}\right)$, com três repetições. A vazão de ar admitida pelo motor nas menores proporções, 0,077 e $0,085 \mathrm{~m}^{3} \mathrm{~s}^{-1}$, proporcionou aumento no consumo de combustível. O maior rendimento na barra de tração e o menor consumo específico de combustível ocorreram quando o trator tracionou a maior carga, 20,5 kN. A eficiência de combustão reduz com o aumento da vazão de ar admita para o motor.

Palavras-chave: Ensaio de tratores, motor ciclo Diesel, rendimento na barra de tração.

\section{ABSTRACT \\ PERFORMANCE OF AN AGRICULTURAL TRACTOR UNDER DIFFERENT LOADS AND FLOWS AIR ADMITTED BY ENGINE}

The aim of this study was to evaluate the energy performance, the performance in the drawbar and combustion efficiency in a Diesel cycle engine of an agricultural tractor using different loads on the draw bar and flow of air entering the feeding system. Thus, an experiment was set up in a completely randomized design in a factorial $5 \mathrm{x} 4$, consisting of different loads on the draw bar of $(2.7,7.4,11.9,15.5$ and $20.5 \mathrm{kN})$ and different air flow admitted by the engine $\left(0.077,0.085,0.099\right.$ and $\left.0.109 \mathrm{~m}^{3} \mathrm{~s}^{-1}\right)$, with three replications. The air flow permitted by the engine in smaller proportions, 0.077 and $0.085 \mathrm{~m}^{3} \mathrm{~s}^{-1}$, resulted in increased fuel consumption. The highest performance in the drawbar and the lowest specific fuel consumption occurred when the tractor pulled the largest load, $20.5 \mathrm{kN}$. The combustion efficiency decreases with increasing air flow admitted to the engine.

Keywords: Tractor test, Diesel cycle engine, performance in the draw bar.

Recebido para publicação em 22/06/2015. Aprovado em 27/04/2016.

1 - Engenheiro Mecânico, Professor do SENAI/Roberto Mange-GO, fabioengenheiromec@gmail.com

2 - Engenheiro Agrícola, Professor da UEG/CCET-GO, fialhoreis@ueg.br

3 - Engenheiro Agrícola, Professor da UEG/CCET-GO, rodneycouto@agricola.eng.br

4 - Engenheiro Agrícola, Professor da UNEMAT/Campus Nova Xavantina-MT, vandoirholtz@hotmail.com 


\section{INTRODUÇÃO}

Uma das principais funções dos tratores agrícolas é transformar a energia contida no combustível e fornecê-la, por meio da barra de tração, para tracionar máquinas e implementos agrícolas (GABRIEL FILHO et al., 2010).

A utilização correta do conjunto motomecanizado, trator-equipamento, pode gerar uma significativa economia de consumo de energia e, portanto, menor custo operacional e maior lucro para a empresa (MONTEIRO et al., 2013a).

Nos motores Diesel aspirados que equipam os tratores agrícolas, o ar é succionado por meio de um filtro purificador para o interior dos cilindros durante o movimento descendente dos pistões. $\mathrm{O}$ ar admitido nos cilindros, ao ser comprimido na câmara de combustão, rapidamente atinge elevadas temperaturas e, quando o óleo Diesel é pulverizado no ar comprimido e aquecido, desenvolve-se a combustão (MIALHE, 1980).

Em condições normais de funcionamento dos motores Diesel, os cilindros não são totalmente preenchidos, devido à dificuldade do ar passar através do filtro, das tubulações de admissão e das passagens estreitas das válvulas (CAMARGO, 2004).

Devido à natureza do ambiente de utilização do trator agrícola, com presença de poeira, terra e resíduos culturais, o filtro de ar fica passível de entupimento e consequente obstrução. $\mathrm{O}$ ar admitido pelo motor Diesel turboalimentado deve possuir as seguintes características: deverá ser limpo, livre de sujeiras e o mais resfriado possível (OGBONNAYA et al., 2010).

Quando o filtro de ar encontra-se parcialmente obstruído, uma menor quantidade de ar é encaminhada para o interior do coletor de admissão, influenciando nos parâmetros de desempenho do motor, como por exemplo, no consumo de combustível, pois a saturação do elemento filtrante faz com que o propulsor tenha que realizar maior força para puxar o ar.

A mensuração da quantidade de combustível consumida é um dos mais importantes aspectos da avaliação do rendimento de um motor, ou seja, do seu desempenho como máquina térmica conversora de energia (MIALHE, 1996).
Cunha et al. (2012), avaliando o desempenho energético de um trator com grade aradora de arrasto, na operação de preparo periódico de solo, concluiu que houve uma diminuição do consumo específico com o aumento da profundidade de trabalho, ou seja, com o aumento da carga. Conclusões semelhantes foram feitas por Toledo et al. (2009). Baixos valores de consumo específico de combustível significam a otimização do desempenho do motor, da eficiência trativa e da adequação do equipamento à fonte de potência (LYNE et al., 1984).

O principal ponto a ser observado nos tratores agrícolas é o desempenho na barra de tração (ZOZ e GRISSO, 2003). Nesse sentido, Monteiro et al. (2011) e Monteiro et al. (2013b) demonstraram que o rendimento na barra de tração pode ser frequentemente usado para comparar ou avaliar tratores.

A combustão da mistura ar - combustível no interior do motor é um dos processos que controlam a potência, eficiência e a produção de gases poluentes (HEYWOOD, 2011).

Sendo assim este trabalho teve como objetivo avaliar, em uma pista de asfalto, o desempenho operacional e a eficiência de combustão em um motor de ciclo Diesel de um trator agrícola, utilizando diferentes vazões de entrada de ar no sistema de alimentação e cargas na barra de tração.

\section{MATERIAL E MÉTODOS}

Os ensaios foram realizados em uma pista com $100 \mathrm{~m}$ de comprimento útil e $6 \mathrm{~m}$ de largura, revestida com pavimento asfáltico, sem declividade no sentido do comprimento e nivelada na largura, contida nas vias de acesso à Universidade Estadual de Goiás (UEG) Campus Anápolis de Ciências Exatas e Tecnológicas Henrique Santillo (CCET). As coordenadas geográficas da pista são: $17^{\circ} 43^{\prime} 19^{\prime \prime} \mathrm{S}$ e $48^{\circ} 09^{\prime} 35^{\prime \prime} \mathrm{W}$ e altitude de $1017 \mathrm{~m}$.

No momento de realização dos ensaios a temperatura ambiente foi de $32{ }^{\circ} \mathrm{C}$ e a pressão atmosférica de $89 \mathrm{kPa}$.

Para avaliação do desempenho energético e da eficiência de combustão no motor de ciclo Diesel do trator, foram utilizadas diferentes cargas na barra de tração e vazões de ar admitida no sistema

\section{REVENG}

$$
\text { 111-119p. }
$$

ENGENHARIA NA AGRICULTURA, VIÇOSA - MG, V.24 N.2, MARÇO / ABRIL 2016 
de alimentação. Assim, montou-se um experimento em delineamento inteiramente casualizado no esquema fatorial $5 \times 4$ constituído por diferentes cargas na barra de tração do trator: 2,$7 ; 7,4 ; 11,9$; 15,5 e $20,5 \mathrm{kN}$ e diferentes vazões de ar admitidas pelo motor: 0,$077 ; 0,085 ; 0,099$ e $0,109 \mathrm{~m}^{3} \mathrm{~s}^{-1}$, com três repetições.

Para realização dos ensaios foi utilizado um trator New Holland modelo TT4030, ano 2010, com 430 horas de trabalho, possuindo tração dianteira auxiliar (TDA) e massa total, com lastros, de 3830 $\mathrm{kg}$. O trator possui um motor ciclo Diesel de quatro cilindros e quatro tempos, com aspiração natural de ar, sistema de injeção de combustível com bomba injetora rotativa, sistema de arrefecimento a água, cilindrada total de $3908 \mathrm{~cm}^{3}$ com potência nominal de $55,1 \mathrm{~kW}(75 \mathrm{cv})$ e pneus dianteiros e traseiros de construção diagonal, modelo Dyna torque II, com especificações técnicas 11,2-24R1 e 16,9-30R1, respectivamente.

A temperatura de trabalho do motor foi de $82{ }^{\circ} \mathrm{C}$ e a do óleo do motor $65^{\circ} \mathrm{C}$, sendo esta medida por um termopar instalado nos filtros de óleo.

Todos os ensaios foram realizados após a aplicação e estabilização da carga de tração oriunda da utilização de um trator de carga. Como reboque foi utilizado um trator New Holland modelo TM7010, com potência nominal de 104 kW (141 $\mathrm{cv})$, tracionado por meio de um cabo de aço de 19 $\mathrm{mm}$ com o trator ensaiado.

A distância entre o trator ensaiado e o trator de carga estava entre 3 a 4 vezes em comparação à distância entre eixos do trator ensaiado, conforme Mialhe (1996).

As variações de marchas no trator de reboque provocaram trações diferenciadas na célula de carga montada na barra de tração do trator ensaiado.

Os valores de força na barra de tração foram obtidos por meio de uma célula de carga marca Excel, modelo RS-5000, capacidade nominal de $50 \mathrm{kN}$, com possibilidade de sobrecarga admissível para atuações esporádicas e eventuais de até $150 \%$ da carga nominal. Os valores de força de tração foram obtidos diretamente em Newton (N) e armazenados pelo sistema de aquisição de dados.

Os dados foram armazenados em um datalogger, modelo CR800 da marca Campbell Scientific INC, alimentado por uma bateria de 12 volts e $7 \mathrm{Ah}$. A aquisição dos dados foi realizada por meio de um programa desenvolvido pelo software PC $200 \mathrm{~W}$ versão 4.0, disponibilizado pela empresa Campbell
Scientific INC.

Para alterar a vazão de ar admitida pelos cilindros, durante o processo de combustão, foram acoplados na entrada do filtro de ar quatro tubos com diâmetros internos pré-determinados, com o objetivo de provocar perdas de carga, simulando situações de obstrução parcial do filtro de ar comuns em operações agrícolas, conforme Figura 1. Para tanto, esta variação restritiva foi de 20,40 , 60 e $80 \%$, em relação ao diâmetro original.

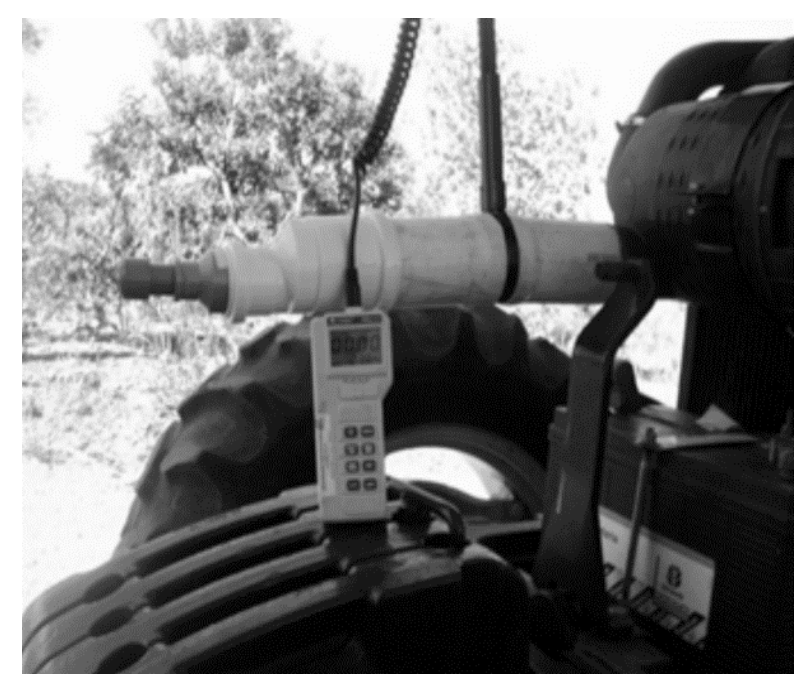

Figura 1. Estrutura montada para restrição da entrada de ar (diferentes vazões) com anemômetro utilizado para medir a velocidade do ar.

Para mensurar a velocidade com que o ar era admitido, um anemômetro portátil Minipa Modelo MDA-11, de palheta giratória com $100 \mathrm{~mm}$ e capacidade para medição entre 0,0 a $30 \mathrm{~m} \mathrm{~s}^{-1}$ foi instalado logo após a saída de cada adaptador. Desse modo, com os valores de velocidade do ar e área de cada tubo foi possível calcular a vazão de ar admitida para o motor, utilizando a equação da continuidade (Equação 1).

$\mathrm{Q}=\mathrm{V} \times \mathrm{A}$

em que,

$\mathrm{Q}$ = vazão de ar admitida para o interior dos cilindros do motor $\left(\mathrm{m}^{3} \mathrm{~s}^{-1}\right)$; $\mathrm{V}=$ velocidade de deslocamento do $\operatorname{ar}\left(\mathrm{m} \mathrm{s}^{-1}\right)$; e $\mathrm{A}=$ área do adaptador conforme percentual de restrição $\left(\mathrm{m}^{2}\right)$. 
A potência na barra de tração foi calculada conforme a Equação 2.

$\mathrm{P}_{\mathrm{BT}}=\frac{\mathrm{F}_{\mathrm{t}} \times \mathrm{V}}{3,6}$

em que,

$\mathrm{P}_{\mathrm{BT}}=$ Potência na barra $(\mathrm{kW})$;

$\mathrm{F}_{\mathrm{t}}=$ Força média na barra de tração $(\mathrm{kN})$; e

$\mathrm{V}=$ Velocidade de deslocamento $\left(\mathrm{km} \mathrm{h}^{-1}\right)$.

O rendimento na barra de tração foi calculado pela Equação 3.

$\eta_{\mathrm{BT}}=\frac{\mathrm{P}_{\mathrm{BT}}}{\mathrm{P}_{\mathrm{m}}} \times 100$

em que,

$\eta=$ Rendimento na barra de tração (\%);

$\mathrm{P}_{\mathrm{BT}}^{\mathrm{BT}}=$ Potência na barra de tração $(\mathrm{kW})$; e

$\mathrm{P}_{\mathrm{m}}=$ Potência do motor fornecida pelo fabricante $(\mathrm{kW})$.

A patinagem das rodas motrizes do trator foi determinada pela diferença entre a distância linear percorrida com o trator sem carga e em condição de comboio ao longo do comprimento da pista. Duas estacas com distância de $100 \mathrm{~m}$ foram colocadas na pista. Ao passar pela primeira estaca era feita uma marcação na roda e acompanhada, contando o número de voltas completas realizada pelo pneu, até o fim da pista onde foi feita outra marcação e medida a distância entre as marcações acompanhando o perímetro do pneu.

Para medição do consumo de combustível, utilizou-se dois fluxômetros volumétricos, modelo FLOWMATE OVAL M-III LSF41L0-M2, da fabricante Japonesa Oval Corporation, um instalado entre os filtros e a bomba injetora do motor do trator e o outro no retorno do combustível ao tanque. O princípio de funcionamento consiste em contabilizar a quantidade de volume de combustível por unidade de tempo. Neste caso, o fluxômetro é munido de duas engrenagens ovais que, ao completarem uma volta, deslocam $1 \mathrm{ml} \mathrm{de}$ combustível gerando um pulso elétrico.

Os pulsos elétricos gerados pelo fluxômetro foram convertidos em volume, considerando a vazão de $1 \mathrm{ml}$ pulso $^{-1}$ e o tempo gasto na parcela. O cálculo do consumo horário de combustível foi feito de acordo com a Equação 4.

$\mathrm{C}_{\mathrm{h}}=\frac{\mathrm{N}_{\mathrm{p}} \times 3,6}{\mathrm{t}}$

em que,

$\mathrm{C}_{\mathrm{h}}=$ consumo horário $\left(\mathrm{L} \mathrm{h}^{-1}\right)$;

$\mathrm{N}_{\mathrm{p}}=$ número de pulsos do medidor de combustível (ml); e

$\mathrm{t}=$ tempo de percurso da parcela $(\mathrm{s})$.

O consumo específico de combustível foi determinado conforme Equação 5.

$\mathrm{C}_{\mathrm{e}}=\frac{\mathrm{C}_{\mathrm{h}}}{\mathrm{P}_{\mathrm{b}}} \times \rho$

em que,

$\mathrm{C}_{\mathrm{e}}=$ Consumo específico de combustível $\left(\mathrm{g} \mathrm{kWh}^{-1}\right)$; $\mathrm{C}_{\mathrm{h}}=$ Consumo horário $\left(\mathrm{L} \mathrm{h}^{-1}\right)$;

$\mathrm{P}_{\mathrm{b}}=$ potência média na barra de tração $(\mathrm{kW})$; e $\rho=$ densidade do combustível $\left(\mathrm{g} \mathrm{L}^{-1}\right)$.

Acoplado ao sistema de exaustão do trator, um monitor ambiental, modelo 940 da marca KANE, foi utilizado para determinação da eficiência de combustão. $\mathrm{O}$ equipamento calcula a eficiência da combustão segundo o disposto na norma britânica BS845 (BS, 1987).

As variáveis obtidas foram submetidas à análise de variância pelo teste de $\mathrm{F}$, a $5 \%$ de probabilidade $\mathrm{e}$, quando houve diferença significativa entre os tratamentos, suas médias foram submetidas à análise de regressão. Em todos os procedimentos estatísticos descritos neste trabalho foi utilizado o programa SISVAR 5.3 (FERREIRA, 2011).

\section{RESULTADOS E DISCUSSÃO}

De acordo com a análise de variância, a interação entre a carga na barra de tração e a vazão de entrada de ar no sistema de alimentação do motor apresentou-se de forma significativa para as variáveis de consumo específico de combustível,

\section{REVENG


rendimento na barra de tração e eficiência de combustão. A patinagem das rodas motrizes do trator sofreu influência significativa somente quando houve variação das cargas na barra de tração. Logo, como são fatores quantitativos, todas as variáveis foram avaliadas por meio de regressão.

Considerando a carga de $15,5 \mathrm{kN}$, atuando com uma vazão de $0,110 \mathrm{~m}^{3} \mathrm{~s}^{-1}$, o consumo específico foi de $327,3 \mathrm{~g} \mathrm{kWh}^{-1}$, e esta mesma carga com uma vazão de $0,077 \mathrm{~m}^{3} \mathrm{~s}^{-1}$ proporcionou $352,2 \mathrm{~g} \mathrm{kWh}^{-}$ ${ }^{1}$ de consumo específico, conforme os modelos ajustados para estas cargas (Figura 2A). Desse modo, observou-se $7,1 \%$ a mais no consumo específico quando o trator tracionava a carga de $15,5 \mathrm{kN}$, na menor vazão de entrada de ar no sistema de alimentação do motor.

A.

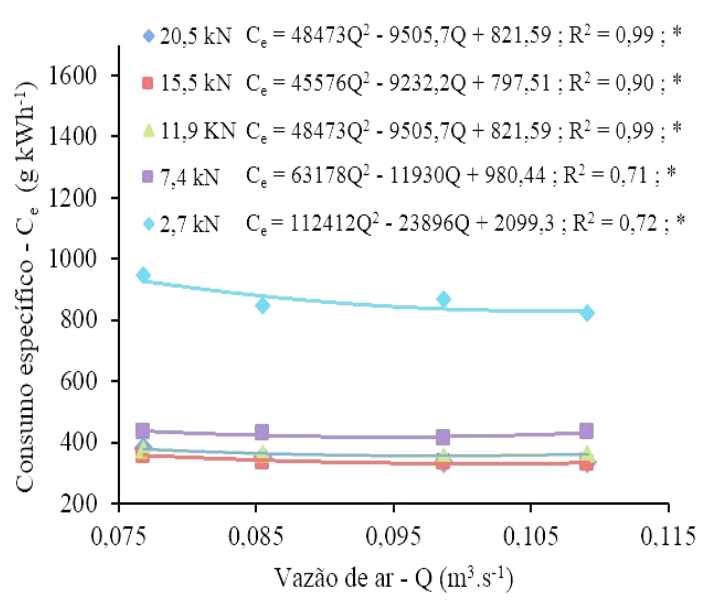

B.

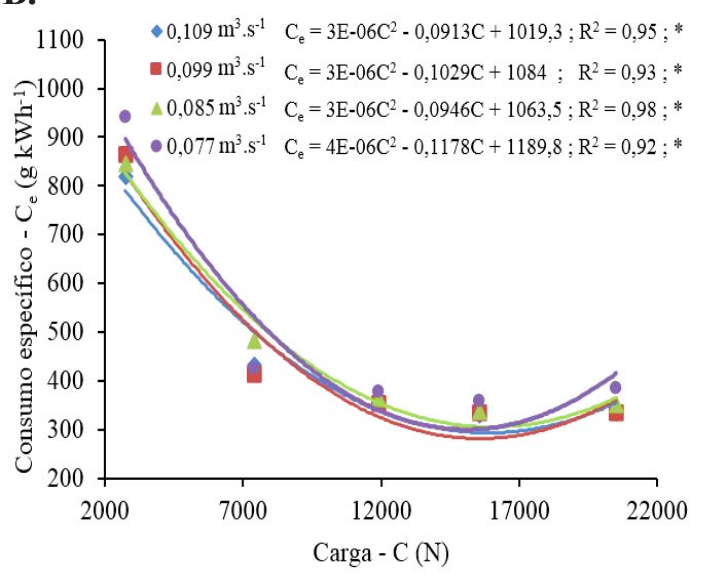

Figura 2. Consumo específico de combustível em função das vazões de ar admitidas pelos cilindros do motor (A); e em função das cargas na barra de tração (B).* Significativo a $5 \%$ de probabilidade, pelo teste " $\mathrm{t}$ ".
Ainda é possível observar que os menores consumos específicos ocorreram com os valores de $20,5 \mathrm{kN}, 15,5 \mathrm{kN}$ e $11,9 \mathrm{kN}$ de força de tração do trator, e o maior para a menor carga, $2,7 \mathrm{kN}$. As cargas $11,9 \mathrm{kN}, 15 \mathrm{kN}$ e $20,5 \mathrm{kN}$ são as que apresentariam os melhores desempenhos nas condições de trabalho em campo, devido ao menor custo demandado por $\mathrm{kW}$ por $\mathrm{h}$, ficando próximos dos valores sugeridos por Serrano (2007).

O comportamento do consumo específico de combustível, conforme foram alteradas as cargas na barra de tração, dentro de cada vazão de ar admitida pelo motor, apresentou comportamento quadrático, conforme Figura 2B. Nota-se no comportamento do gráfico que os menores consumos ocorreram com cargas maiores e que o consumo específico aumentou para todas as vazões, à medida que diminuíram as cargas. Para a vazão de ar de $0,109 \mathrm{~m}^{3} \mathrm{~s}^{-1}$ e carga de $15,30 \mathrm{kN}$, o consumo específico mínimo foi de 324,66 $\mathrm{g} \mathrm{kWh}^{-}$ 1; na vazão de ar de $0,099 \mathrm{~m}^{3} \mathrm{~s}^{-1}$ e carga de 17,15 kN, o consumo específico mínimo foi de 201,63 $\mathrm{g} \mathrm{kWh}^{-1}$; o consumo específico mínimo de 317,74 $\mathrm{g} \mathrm{kWh}^{-1}$ foi obtido na vazão de ar de $0,085 \mathrm{~m}^{3} \mathrm{~s}^{-1}$ e carga de $15,77 \mathrm{kN}$ e, finalmente, para a maior restrição na entrada de ar, com vazão de $0,077 \mathrm{~m}^{3}$ $\mathrm{s}^{-1}$ e carga de $14,72 \mathrm{kN}$, foi verificado um consumo mínimo de $322,50 \mathrm{~g} \mathrm{kWh}^{-1}$. Os menores valores de consumo específico de combustível apresentam melhor aproveitamento energético do combustível consumido quando se eleva a exigência de tração, otimizando o desempenho do motor, da eficiência trativa e da adequação do equipamento à fonte de potência, simultaneamente, conforme Toledo et al. (2009), Salvador et al. (2009).

De acordo com os modelos apresentados observa-se que, para as vazões de 0,077 e $0,109 \mathrm{~m}^{3}$ $\mathrm{s}^{-1}$, na carga de $20,5 \mathrm{kN}$, o motor do trator consumiu 449,00 e $383,00 \mathrm{~g} \mathrm{kWh}^{-1}$, respectivamente, proporcionando $14,7 \%$ na diferença de consumo. A justificativa para este comportamento está no processo de admissão de ar, pois o volume de ar não foi suficiente para preencher os cilindros quando as menores vazões de ar eram admitidas pelo motor. Assim, a formação da mistura ar e combustível foi comprometida no processo de combustão, comportamento que concorda com Cruz (2005) e Souza (2010). 
A vazão de ar admitido pelo motor praticamente não alterou o rendimento da barra de tração (Figura $3 \mathrm{~A})$. Verifica-se que o menor rendimento na barra de tração ocorreu na menor carga, $2,7 \mathrm{kN}$, e o maior rendimento na maior carga, $20,5 \mathrm{kN}$, mostrando que houve melhor aproveitamento da potência disponível na barra para as maiores cargas.

A.

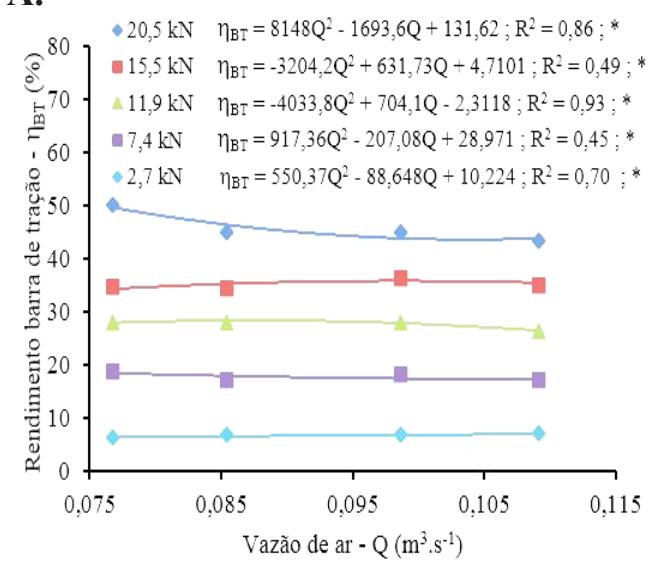

B.

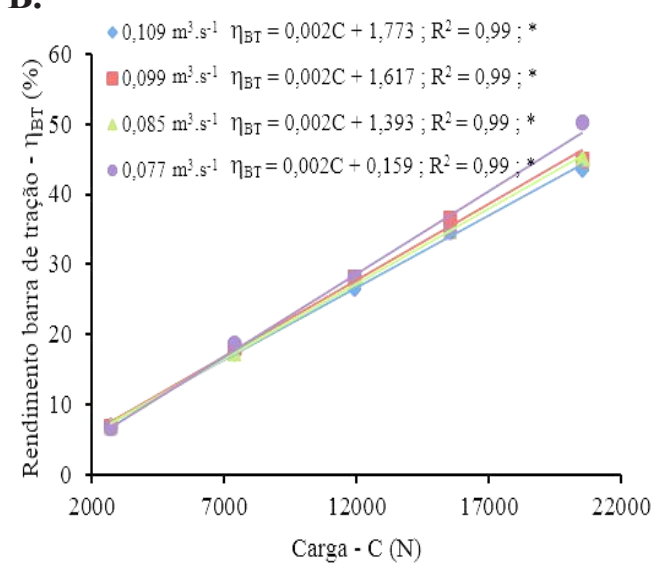

Figura 3. Rendimento na barra de tração em função das vazões de ar admitidas pelos cilindros do motor (A); e em função das cargas na barra de tração (B). * Significativo a 5\% de probabilidade, pelo teste " $\mathrm{t}$ ".

Os rendimentos na barra de tração, conforme foram alteradas as cargas na barra de tração, dentro de cada vazão de ar admitida pelo motor, podem ser vistos na Figura 3B. Observa-se nesta figura características semelhantes para as diferentes quantidades de ar admitido, apresentando menores rendimentos para as menores cargas, e maiores rendimentos para as maiores cargas, ou seja, para todas as vazões o desempenho na barra de tração foi proporcional ao aumento da carga.
Para a carga de $15 \mathrm{kN}$, comparando as vazões de 0,077 e $0,109 \mathrm{~m}^{3} \mathrm{~s}^{-1}$, observou-se $5,1 \%$ a mais de desempenho na barra de tração quando a vazão era de $0,109 \mathrm{~m}^{3} \mathrm{~s}^{-1}$. Quando a carga foi de $20,5 \mathrm{kN}$ obteve-se $3,9 \%$ a mais de rendimento para esta mesma vazão. Esta diferença se deve à interferência que a admissão de ar exerce no processo de combustão, uma vez que a obstrução provocada no sistema de admissão de ar proporcionou redução da potência do motor quando ocorreu menor admissão de ar, argumento que concorda com Leontsinis (1988).

O maior rendimento na barra de tração $(49,5 \%)$ foi obtido para a carga de $20,5 \mathrm{kN}$, valor máximo considerado na barra de tração do trator ensaiado, que se aproxima do valor de rendimento obtido por Monteiro et al. (2013b).

Masiero et al.(2011) determinando o rendimento na barra de tração de diversos tratores agrícolas com tração dianteira auxiliar (4x2 TDA), em pista de concreto, obtiveram um valor médio de $63,2 \%$.

$\mathrm{O}$ aumento da demanda de carga provocado pelo trator de reboque promoveu acréscimo nos valores de patinagem do trator (Figura 4). Os valores recomendados pela norma técnica ASAE EP 496.2 (1999) preconizam níveis de patinagem compreendidos na faixa de 4 a $8 \%$, para obtenção da máxima eficiência de tração, em superfície de concreto. Desse modo, as cargas entre 2,7e 7,4 $\mathrm{kN}$ proporcionam menores valores de patinagem e, consequentemente, melhor eficiência de tração. Entretanto, as maiores cargas proporcionaram valores de patinagem acima dos valores recomendados pela norma citada anteriormente para pista de concreto (asfalto).

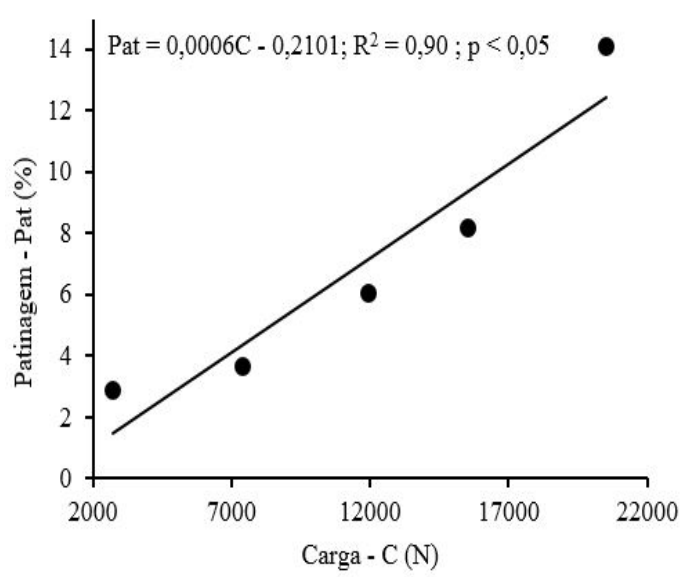

Figura 4. Patinagem do rodado do trator em função das cargas na barra de tração.

\section{REVENG}

111-119p. ENGENHARIA NA AGRICULTURA, VIÇOSA - MG, V.24 N.2, MARÇO / ABRIL 2016 
O incremento das cargas e a tendência de diminuição da vazão tornaram a combustão mais eficiente. A eficiência de combustão para a carga de $7,4 \mathrm{kN}$ foi 3,5\% maior em relação à carga de 2,7 $\mathrm{kN}$, com uma vazão de admissão de ar de $0,109 \mathrm{~m}^{3}$ $\mathrm{s}^{-1}$ (Figura 5A).

A.

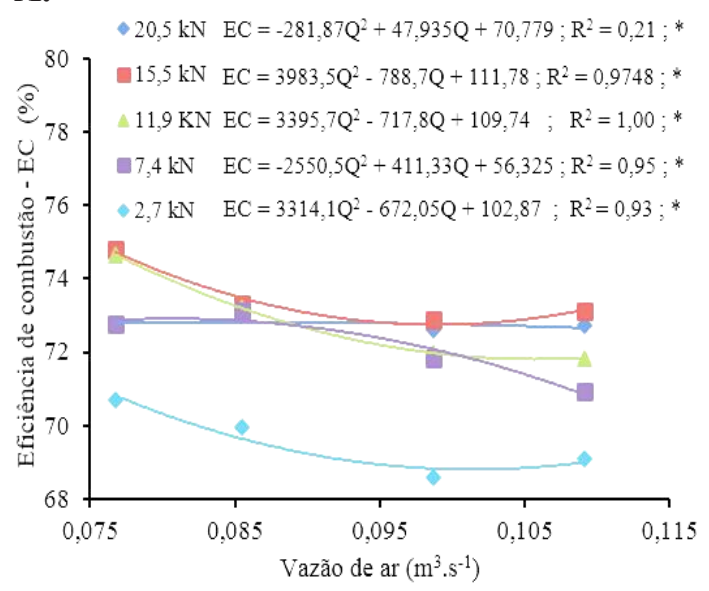

B.

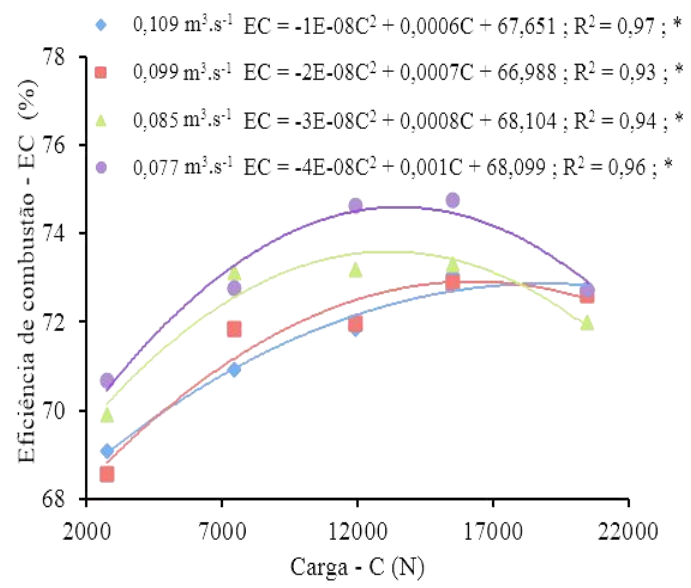

Figura 5. Eficiência de combustão em função das vazões de ar admitidas pelos cilindros do motor (A); e em função das cargas na barra de tração (B). * Significativo a 5\% de probabilidade pelo teste " $\mathrm{t}$ ".

A eficiência de combustão, conforme foram alteradas as cargas na barra de tração dentro de cada vazão de ar admitida pelo motor, apresentou comportamento quadrático, conforme Figura 5B. Para a vazão de ar de $0,109 \mathrm{~m}^{3} \mathrm{~s}^{-1}$ e carga de 30,0 $\mathrm{kN}$, a máxima eficiência de combustão foi de $76,65 \%$; na vazão de ar de $0,099 \mathrm{~m}^{3} \mathrm{~s}^{-1}$ e carga de
$17,5 \mathrm{kN}$, a máxima eficiência de combustão foi de $73,11 \%$; a eficiência máxima de $73,44 \%$ foi obtida na vazão de ar de $0,085 \mathrm{~m}^{3} \mathrm{~s}^{-1}$ e carga de $13,33 \mathrm{kN}$ $\mathrm{e}$, finalmente, para a maior restrição na entrada de ar, com vazão de $0,077 \mathrm{~m}^{3} \mathrm{~s}^{-1}$ e carga de $12,5 \mathrm{kN}$, foi verificado uma eficiência máxima de $74,35 \%$.

Para que ocorra a combustão completa do carbono, hidrogênio e quaisquer outros elementos que constituem o combustível, necessita-se de uma quantidade mínima de ar para que estes elementos se oxidem, a qual é denominada de "ar teórico" (COSTA, 2007). Quando existe um excesso de ar além do necessário na combustão, determinado pela presença do oxigênio nos gases de escape, ocorre redução da eficiência global do processo de combustão (BAZZO, 1995), além do aumento no consumo de combustível, pois o ar que não participa da combustão tende a consumir energia na forma de calor.

Possivelmente essa é a justificativa para o fato das eficiências de combustão serem menores nas maiores vazões de ar admita para o motor.

Conforme enfatiza Guarieiro et al. (2011), a relação ar/combustível no processo de combustão pode ser explorada para uso eficiente do oxigênio e uma das vantagens da otimização desta relação é a redução da emissão de CO.

\section{CONCLUSÕES}

- O menor consumo específico de combustível, 201,63 $\mathrm{g} \mathrm{kWh}^{-1}$, foi obtido na vazão de ar de $0,099 \mathrm{~m}^{3} \mathrm{~s}^{-1}$ combinada com a carga de 17,15 $\mathrm{kN}$;

- Os maiores valores de consumo específico de combustível pelo motor do trator foram obtidos quando se aplicou cargas na barra de tração de 20,5 e 15,4 kN em combinação com as menores vazões de ar comburente admitida pelo motor, 0,077 e $0,085 \mathrm{~m}^{3} \mathrm{~s}^{-1}$;

- O rendimento na barra de tração foi maior quando o trator arrastou a carga de $20,5 \mathrm{kN}$.

- A patinagem foi diretamente influenciada pela carga e apresentou maior valor na carga de $20,5 \mathrm{kN}$;

- A máxima eficiência de combustão, 76,65\%, foi obtida na vazão de ar de $0,109 \mathrm{~m}^{3} \mathrm{~s}^{-1}$ combinada com a carga de $30,0 \mathrm{kN}$. 


\section{AGRADECIMENTOS}

Os autores agradecem à Fundação de Amparo à Pesquisa do Estado de Goiás (FAPEG) pela concessão da bolsa de estudo.

\section{REFERÊNCIAS BIBLIOGRÁFICAS}

AMERICAN SOCIETY OF AGRICULTURAL ENGINEERS. ASAE EP 496.2 DEC98: Agricultural Machinery Management. St. Joseph: American Society of Agricultural Engineers, 1999. p.353-358.

BAZZO, E. Geração de vapor. Florianópolis: Ed. da UFSC, 1995. 216p. (Série didática).

BRITISH STANDARDS. BS 845: Methods for assessing thermal performance of boilers for steam, hot water and high temperature heat transfer fluids. Concise procedure. British Standards Institution: London, 1987. 44p.

CAMARGO, M.N. Potência extra. Cultivar Máquinas, Pelotas, n.26, p.18-22, dez/jan. 2004.

COSTA, Y.J.R. Análise energética e exergética de um motor de combustão interna operando com mistura de Diesel e Gás natural. 2007. 185f. Tese (Doutorado em Engenharia de Processos) Universidade Federal de Campina Grande, Centro de Ciências e Tecnologia, Campina Grande, 2007.

CRUZ, P.T. Avaliação da intensidade de turbulência em motores do Ciclo Otto. 2005. 107f. Dissertação (Mestrado em Ciências Mecânicas) - Universidade de Brasília, Brasília, 2005.

CUNHA, J.P.B.; REIS, E.F.; COUTO, R.F.; HOLTZ, V.; LEONÍDIO, D.M. Efeito de diferentes concentrações de biodiesel no desempenho de um trator em operação de preparo do solo. Revista Agrotecnologia, Anápolis, v.2, n.2, p.53-67, 2012.

FERREIRA, D.F. Sisvar: a computer statistical analysis system. Ciência e Agrotecnologia,
Lavras, v.35, n.6, p.1039-1042, 2011.

GABRIEL FILHO, A.; LANÇAS, K. P.; LEITE, F.; ACOSTA, J. J. B.; JESUINO, P. R. Desempenho de trator agrícola em três superfícies de solo e quatro velocidades de deslocamento. Revista Brasileira de Engenharia Agrícola e Ambiental, Campina Grande, v.14, n.3, p.333-339, 2010.

GUARIEIRO, L.L.N.; VASCONCELLOS, P.C.; SOLCI, M.C. Poluentes atmosféricos provenientes da queima de combustíveis fósseis e biocombustíveis: uma breve revisão. Revista Virtual de Química, Niterói, v.3, n.5, p.434-445, 2011.

HEYWOOD, J.B. Internal combustion engines fundamentals. Noida: Tata McGraw-Hill Education, 2011.960p.

LEONTSINIS, E. Óleo Diesel. In: Curso de formação de informação sobre combustíveis e combustão. 11 ${ }^{\mathrm{a}}$ Ed. Rio de Janeiro: IBP, 1988. p.65-77.

LYNE, P.W.L.; BURT, E.C.; MEIRING, P. Effect of tire and engine parameters on efficiency. Transactions of ASABE, Saint Joseph, v.27, n.1, p.5-7, 1984.

MASIERO, F.C.; LANÇAS, K.P.; MONTEIRO, L.A. Determinação do rendimento na barra de tração de tratores agrícolas com tração dianteira auxiliar (4x2 TDA). Revista Energia na Agricultura, Botucatu, v.26, n.4, p.55-73, 2011.

MIALHE, L.G. Máquinas agrícolas: Ensaios e certificação. Piracicaba: Fundação de estudos agrários Luiz de Queiroz, 1996. 722 p.

MIALHE, L.G. Máquinas motoras na agricultura. São Paulo: Ed. Universidade de São Paulo, v.1, 1980. 289p.

MONTEIRO, L.A.; LANÇAS, K.P.; GUERRA, S.P.S. Desempenho de um trator agrícola equipado com pneus radiais e diagonais com três níveis de lastros líquidos. Engenharia Agrícola, Jaboticabal, 
v.31, n.3, p.551-560, 2011.

MONTEIRO, L.A.; ALBIERO, D.; CHIODEROLI, C.A.; LOUREIRO, D.R. Segurança e operação de tratores agrícolas. Fortaleza: Universidade Federal do Ceará. Laboratório de Investigação de Acidentes com Máquinas Agrícolas-LIMA. 2013a. 77p.

MONTEIRO, L. A.; ALBIERO, D; SOUZA, F. H.; MELO, R.P.; CORDEIRO, I. M. Rendimento na barra de tração de um trator agrícola com diferentes relações de peso e potência. Revista Ciência Agronômica, Fortaleza, v.44, n.1, p.70-75, 2013b.

OGBONNAYA, E. A.; UGWU, H.U.; JOHNSON, K.T.; JOHNSON， C.A.N.; ORJI， C.U. Computerized Condition Monitoring of a Diesel Engine Through Air Inlet Filter Analysis. Journal of Engineering and Applied Sciences, Peshawar, v.5, n.3, p.201-205. 2010.

SALVADOR, N.; MION, R.L.; BENEZ, S.H. Consumo de combustível em diferentes sistemas de preparo periódico realizados antes e depois da operação de subsolagem. Ciências e Agrotecnologia, Lavras, v.33, n.3, p.870-874, 2009.
SILVEIRA, G.M.; SIERRA, J.G. Eficiência energética de tratores agrícolas fabricados no Brasil. Revista Brasileira de Engenharia Agrícola e Ambiental, Campina Grande, v.14, n.4, p.418-424, 2010.

SERRANO, J.M.P.R. Desempenho de tratores agrícolas em tração. Pesquisa Agropecuária Brasileira, Brasília, v.42, n.7, p.1021-1027, 2007.

SOUZA, G.R. Estudo experimental e numérico do sistema de admissão de um motor de combustão interna. 2010. 141f. Tese (Doutorado em Engenharia Mecânica)-Universidade de São Paulo, Departamento de Engenharia Mecânica, São Carlos, 2010.

TOLEDO, A.; TABILE, R.A.; GROTTA, D.C.C.; CORTEZ, J.W.; FURLANI, C.E.A. Desempenho de trator agrícola atuando com $5 \%$ de biodiesel em operação de semeadura. Revista Engenharia na Agricultura, Viçosa, v.17, n.03, p.205-214, 2009.

ZOZ, F.M; GRISSO, R.D. Traction and tractor performance. Louisville: ASAE, 2003. 46p. 